\title{
Randomised double blind trial of single dose doxycycline for treating cholera in adults
}

\author{
A N Alam, N H Alam, T Ahmed, D A Sack
}

Abstract

Objective-To compare the efficacy of a single dose of doxycycline ( 200 or $300 \mathrm{mg}$ ) with the standard mutiple doses of tetracycline in patients with cholera.

Design-Randomised double blind controlled trial. Patients were given a single $200 \mathrm{mg}$ dose of doxycycline, a single $300 \mathrm{mg}$ dose of doxycycline, or multiple doses of tetracycline $(500 \mathrm{mg}$, six hourly intervals).

Setting-Hospital in Bangladesh treating diarrhoea.

Patients-261 Patients aged over 15 admitted to the hospital with severe dehydration due to acute watery diarrhoea associated with Vibrio cholerae. All vibrios isolated from the stools and rectal swabs of patients, including those patients with prolonged excretion of vibrios, were sensitive to tetracycline. The stools of all patients at admission were negative for shigella and salmonella.

Interventions-All patients received rapid intravenous acetate solution for the first four hours after admission to hospital. They were then entered in the study and randomised. Oral rehydration was started immediately after the intravenous treatment. If signs of severe dehydration reappeared during oral treatment patients were given rapid intravenous acetate solution until dehydration was fully corrected.

Main outcome measures-Stool output in first 24 hours and till diarrhoea stopped, total intake of oral rehydration fluid, duration of diarrhoea, and excretion of vibrio after receiving antibiotic treatment.

Results-The median stool outputs during the first 24 hours ( $275 \mathrm{ml} / \mathrm{kg}$ body weight) and till diarrhoea stopped (296 ml/kg body weight) were significantly higher in patients receiving $200 \mathrm{mg}$ doxycycline as a single dose than in patients receiving either standard tetracycline $(242 \mathrm{ml} / \mathrm{kg}$ body weight and $254 \mathrm{ml} / \mathrm{kg}$ body weight) or $300 \mathrm{mg}$ doxycycline ( $226 \mathrm{ml} / \mathrm{kg}$ body weight and $255 \mathrm{ml} / \mathrm{kg}$ body weight). Similarly, median consumption of oral rehydration solution (18.45 l) was significantly higher in patients receiving $200 \mathrm{mg}$ doxycycline than in patients receiving either $300 \mathrm{mg}$ doxycycline $(16 \cdot 10$ l) or standard tetracycline (14.801). Almost equal numbers of patients in each group required unscheduled intravenous acetate solution to correct dehydration during antibiotic treatment. Patients treated with doxycycline (low or high dose), however, had more prolonged excretion of bacteria.

Conclusions - A single $300 \mathrm{mg}$ dose of doxycycline is as effective as the standard multiple dose tetracycline treatment for cholera in terms of stool output, duration of diarrhoea, vomiting, and requirement for oral rehydration solution.

\section{Introduction}

Patients with cholera are effectively treated with intravenous and oral rehydration fluids. Simultaneous administration of antibiotics, however, considerably reduces the stool volume, duration of diarrhoea, and excretion of vibrio in the stool, thereby decreasing the need for intravenous fluids and nursing care. Various doses of tetracycline are effective in the treatment of cholera. ${ }^{12}$ Doxycycline, a long acting tetracycline, is effective clinically when given as a single dose of 200 $\mathrm{mg}$ or $300 \mathrm{mg}^{34}$ or over four days. ${ }^{5}$ Multiple doses of tetracycline, however, have been found to be better than single doses of tetracycline or doxycycline, particularly in shortening the duration of excretion of vibrio in the stool. ${ }^{46}$ For inpatients effective single dose treatment would save nursing time and reduce the cost of hospital treatment. In outpatient clinics or in the community during an epidemic multiple dose treatment is difficult to supervise and a single dose would, if effective, be preferable.

Doxycycline seems to be an excellent antibiotic for cholera (except in the unusual case of Vibrio cholerae resistant to tetracycline). Its intestinal absorption is not impaired by the presence of food, and nearly all of a dose is absorbed. As it has a half life of 15-20 hours therapeutic plasma concentrations persist much longer than with tetracycline. For infections that are normally treated with doses of tetracycline every six hours doxycycline can be given once daily. Doxycycline is excreted through the kidneys and liver, but it is also excreted directly across the small intestinal mucosa, placing the antibiotic where it can be most effective. Because of the multiple excretion mechanisms toxic concentrations do not usually accumulate, even in patients with renal or hepatic failure. One disadvantage of doxycycline is its association with nausea and vomiting if given orally. This side effect is dose related (being more common with a daily dose of $300 \mathrm{mg}$ than $200 \mathrm{mg}$ ) and can be lessened by giving the drug with or after food. Treatment with doxycycline is now cheaper than that with tetracycline.

Recently, the World Health Organisation has been revising its recommendations on the use of doxycycline in cholera with special reference to situations where single dose treatment would be especially appropriate, including rural treatment centres, refugee camps, and other settings where supervision of treatment is minimal. Although several studies have shown the efficacy of both single and multiple doses of doxycycline, no single study has directly compared the antibiotic treatment options or evaluated the degree to which nausea and vomiting might interfere with treatment with higher doses $(300 \mathrm{mg}$ ) of doxycycline. We therefore undertook this study.

\section{Patients and methods}

Two hundred and sixty one patients aged over 15 with a clinical history of acute watery diarrhoea of less than 24 hours' duration and whose stools were found to contain $V$ cholerae by dark field microscopy were eligible for the study. These patients reported to this centre from Dhaka and its suburbs from June 1986 to December 1987. Patients were excluded if they had taken antibiotics within one week of admission to hospital, were pregnant, or had other systemic illnesses or if cultures of their stools or rectal swabs, or both, were negative for $V$ cholerae. The study protocol was approved by the human ethical review and research
Correspondence to: Dr Alam. 
review committees of the centre and WHO. Written consent was obtained from each patient before selection for the study.

Three previous studies of similar patients given antibiotics showed mean total stool outputs of $250 \mathrm{ml} /$ $\mathrm{kg}$ body weight with a standard deviation of $100 \mathrm{ml} / \mathrm{kg}$ body weight. ${ }^{134}$ Based on these studies a sample size of 82 per group was estimated to be necessary to detect a significant difference between mean purging rates $\geqslant 50$ $\mathrm{ml} / \mathrm{kg}$ body weight (at $5 \%$ significance level and power of $80 \%$ ). Another 15 patients were recruited to each group to account for deviated course or drop outs.

On admission to the observation ward patients were weighed and their clinical signs recorded to permit correct assessment of dehydration. During the first four hour observation period they were rehydrated with isotonic intravenous Dhaka solution (containing sodium $133 \mathrm{mmol} / 1$, potassium $13 \mathrm{mmol} / 1$, bicarbonate equivalent $48 \mathrm{mmol} / \mathrm{l}$, and chloride $99 \mathrm{mmol} / \mathrm{l}$ ) to replace the fluid deficit. Consenting patients whose purging rate exceeded $20 \mathrm{ml} / \mathrm{kg}$ body weight during the four hour basal period were then admitted to the study and were maintained with a glucose oral rehydration solution to match the stool output. They were then assigned to one of three treatment regimens: group 1 received mutiple doses of tetracycline $(500 \mathrm{mg}$ every six hours; eight doses), group 2 single doses of doxycycline $(300 \mathrm{mg})$, and group 3 single doses of doxycycline $(200 \mathrm{mg}$ )

Preparations of the drugs were provided by Pfizer, Bangladesh, as identical capsules for all three groups. The drugs were labelled separately, and eight capsules were put into numbered identical envelopes; patients randomised to single doses of doxycycline received the active drug in the first dose and a starch placebo in subsequent doses. Randomisation was incorporated into the serial number of the envelopes containing medicine. These numbers corresponded to the order of patients entering the trial so that the first patient received capsules from envelope number one. The code for the drugs was kept at the headquarters of WHO in Geneva, and a sealed copy of the code was also sent to the director of the centre to be kept in a locked cabinet.

The first capsules were given to patients within four to six hours of their admission to the ward after they were adequately hydrated and had taken some simple foods (rice, vegetables, fish, lentils, bread, banana, etc). All patients were carefully monitored daily for any side effects. Intake of rehydration fluid, stool output, and vital signs were recorded every eight hours. The number of episodes and volume of vomiting after admission to the study ward were carefully determined.

A stool specimen was obtained on admission for

TABLE I-Characteristics of patients on admission to hospital with cholera

\begin{tabular}{|c|c|c|c|}
\hline & \multicolumn{3}{|c|}{ Treatment group } \\
\hline & $\begin{array}{c}\text { Tetracycline } \\
(\mathrm{n}=84)\end{array}$ & $\begin{array}{l}\text { Doxycycline (300 mg) } \\
\qquad(\mathrm{n}=80)\end{array}$ & $\begin{array}{c}\text { Doxycycline }(200 \mathrm{mg}) \\
\qquad(\mathrm{n}=82)\end{array}$ \\
\hline \multicolumn{4}{|l|}{ Age (years): } \\
\hline Median & 25 & 25 & 25 \\
\hline Range & $15-55$ & $15-60$ & $12-55$ \\
\hline $\operatorname{Sex}(M / F)$ & $52 / 32$ & $48 / 32$ & $48 / 34$ \\
\hline \multicolumn{4}{|c|}{ Weight at admission $(\mathrm{kg})$ : } \\
\hline Median & 40 & 40 & 39 \\
\hline Range & $25-70$ & $27-60$ & $28-58$ \\
\hline \multicolumn{4}{|c|}{ Duration of diarrhoea before admission (h): } \\
\hline Median & 14 & 14 & 13 \\
\hline Range & $4-30$ & $3-30$ & $4-30$ \\
\hline \multicolumn{4}{|c|}{ No of stools passed since onset: } \\
\hline Median & 16 & 20 & 20 \\
\hline Range & $5-40$ & $4-60$ & $5-50$ \\
\hline \multicolumn{4}{|c|}{ No of vomits since onset: } \\
\hline Median & 6 & 6 & 7 \\
\hline Range & $1-25$ & $1-30$ & $1-30$ \\
\hline \multicolumn{4}{|c|}{ Dehydration on admission to the study: } \\
\hline Mild & 1 & & \\
\hline Moderate & 12 & 13 & 10 \\
\hline Severe & 71 & 67 & 72 \\
\hline
\end{tabular}

examination by dark field microscopy and for culture of $V$ cholerae, salmonella, and shigella. Campylobacter jejuni was not sought in the culture. A catheter specimen of the stool or rectal swab was obtained each morning for culture of $V$ cholerae. The specimens for dark field microscopy were examined immediately and after four hours' incubation $\left(37^{\circ} \mathrm{C}\right)$ in alkaline peptone water. A presumptive report of $V$ cholerae was made if the examination showed organisms with typical motility and if this motility was inhibited by $V$ cholerae antiserum.

For culture of $V$ cholerae inoculation was made in tellurite taurocholate gelatin agar both directly and after six hours' incubation in alkaline peptone water. $V$ cholerae was reported if typical colonies were observed (positive reactions to gelatinase and tellurite and appeared translucent) that agglutinated in $V$ cholerae 01 antiserum. The isolates were further characterised by agglutination with specific antiserum and chicken red cells and by sensitivity to polymixin $B$.

All patients were observed closely until their diarrhoea had stopped for at least 24 hours and their faecal cultures had been negative for $V$ cholerae for two consecutive days. Bacteriological relapse was defined as the isolation of $V$ cholerae from the stool or rectal swab of a patient who had had negative cultures on two preceding days. Bacteriological failure was considered to have occurred in patients in whom vibrio excretion in the stool was prolonged and continued throughout the study. Diarrhoea was defined as ended when a patient had not passed a watery stool for eight hours. Therapeutic failure was considered to have occurred in patients in whom signs of dehydration reappeared and intravenous fluid treatment had to be restarted.

Finger prick samples of blood were obtained from each patient to estimate packed cell volume and plasma specific gravity (TS meter, American Optical) on admission and two days later to determine the degree of dehydration.

Statistical analyses were done by Wilcoxon's rank sum test, Kruskal-Wallis one way analysis of variance, and $\chi^{2}$ test, with statistical package for the social sciences (SPSS PC + ).

\section{Results}

Two hundred and sixty one patients were initially recruited to the study. Fifteen were excluded because their faecal cultures were negative for $V$ cholerae. The characteristics of the three groups of study patients at admission were comparable (table I). Of the 246 patients, 217 were treated successfully, but therapeutic or bacteriological failure, or both, occurred in 29.

The primary objective of the study was to compare the reference group receiving multiple dose tetracycline with the two groups receiving doxycycline. The results of Kruskal-Wallis one way analysis of variance for stool output in the first 24 hours $(p=0.016)$, total stool output till diarrhoea stopped $(p=0 \cdot 041)$, and total intake of oral rehydration solution $(p=0.020)$ were significant. Pairwise treatment comparisons were then made with Wilcoxon's rank sum test between the tetracycline group and the two doxycycline groups.

Table II shows the clinical characteristics of the patients after intervention. No significant difference was observed between patients receiving conventional tetracycline (group 1) and high dose doxycycline (group 2) for stool output during the first 24 hours, total stool output till diarrhoea stopped, total intake of oral rehydration solution till diarrhoea stopped, duration of diarrhoea, or number of patients who vomited. Patients receiving low dose doxycycline had a significantly larger stool output till diarrhoea stopped 


\begin{tabular}{|c|c|c|c|c|c|c|c|}
\hline & \multicolumn{3}{|c|}{ Treatment group } & \multicolumn{2}{|c|}{$\begin{array}{l}95 \% \text { Confidence interval for } \\
\text { difference between medians }\end{array}$} & \multicolumn{2}{|c|}{$\mathrm{p}$ Value for } \\
\hline & $\begin{array}{l}\text { Tetracycline } \\
(\mathrm{n}=84)\end{array}$ & $\begin{array}{l}\text { Doxycycline } \\
(300 \mathrm{mg}) \\
(\mathbf{n}=80)\end{array}$ & $\begin{array}{l}\text { Doxycycline } \\
\quad(200 \mathrm{mg}) \\
(\mathrm{n}=82)\end{array}$ & $\begin{array}{l}\text { Tetracycline } v \\
\text { doxycycline } \\
(300 \mathrm{mg})^{\star}\end{array}$ & $\begin{array}{c}\text { Tetracycline } v \\
\text { doxycycline }(200 \mathrm{mg})\end{array}$ & $\begin{array}{l}\text { Tetracycline } v \\
\text { doxycycline } \\
(300 \mathrm{mg})\end{array}$ & $\begin{array}{c}\text { Tetracycline } v \\
\text { doxycycline } \\
(200 \mathrm{mg})\end{array}$ \\
\hline No of patients who vomited ${ }^{\star}$ & 18 & 24 & 32 & & & & \\
\hline Stool output in first $24 \mathrm{~h}(\mathrm{ml} / \mathrm{kg}$ body weight $)$ & $242(149,323)$ & $226(159,310)$ & $275(201,357)$ & $-29 \cdot 3$ to $49 \cdot 3$ & $-76 \cdot 6$ to $-4 \cdot 3$ & 0.60 & 0.032 \\
\hline Total stool output till diarrhoea stopped (ml/kg body weight) & $254(159,377)$ & $255(175,349)$ & $296(219,420)$ & $-36 \cdot 4$ to $57 \cdot 1$ & $-93 \cdot 1$ to $-0 \cdot 4$ & $0 \cdot 71$ & 0.052 \\
\hline Duration of diarrhoea $(h)$ & $32(24,48)$ & $32(24,47)$ & $40(24,48)$ & $-5 \cdot 0$ to 5.0 & -8.0 to 0.0 & 0.97 & $0 \cdot 170$ \\
\hline Total intake of oral rehydration solution (1) & $14 \cdot 8(10,22)$ & $16 \cdot 1(10,22)$ & $18 \cdot 45(15,23)$ & $-3 \cdot 5$ to $2 \cdot 0$ & $-6 \cdot 0$ to $-1 \cdot 0$ & 0.54 & 0.007 \\
\hline Weight at discharge $(\mathrm{kg})$ & $43(38,47)$ & $44(40,48)$ & & $42(38,47)$ & & 0.36 & $0 \cdot 69$ \\
\hline No of patients receiving unscheduled intravenous fluids & 10 & 8 & & 9 & & & \\
\hline
\end{tabular}

^Difference between tetracycline group and doxycycline $(300 \mathrm{mg})$ and doxycycline $(200 \mathrm{mg})$ groups were significant, $\mathrm{p}=0 \cdot 047\left(\chi^{2}=3 \cdot 94\right)$.

TABLE III - Number of patients with excretion of $V$ cholerae in stool for four consecutive days

\begin{tabular}{|c|c|c|c|c|c|}
\hline \multirow[b]{2}{*}{ Day } & \multicolumn{3}{|c|}{ Treatment group } & \multicolumn{2}{|c|}{$\mathrm{p}$ Value for } \\
\hline & Tetracycline & $\begin{array}{l}\text { Doxycycline } \\
(300 \mathrm{mg})\end{array}$ & $\begin{array}{l}\text { Doxycycline } \\
(200 \mathrm{mg})\end{array}$ & $\begin{array}{c}\text { Tetracycline } v \\
\text { doxycycline }(300 \mathrm{mg})\end{array}$ & $\begin{array}{c}\text { Tetracycline } v \\
\text { doxycycline }(200 \mathrm{mg})^{\star}\end{array}$ \\
\hline 1 & 35 & 49 & 50 & 0.01 & 0.01 \\
\hline 2 & 6 & 15 & 18 & 0.03 & 0.007 \\
\hline 3 & 2 & 8 & 5 & 0.04 & NS \\
\hline 4 & 1 & 7 & 3 & 0.02 & NS \\
\hline
\end{tabular}

^Difference between two doxycycline groups was not significant for any of the four days.

and during the first 24 hours and higher consumption of oral rehydration solution during treatment than patients receiving standard tetracycline. The proportion of patients who vomited was higher in the doxycycline groups combined than in the tetracycline group $\left(\chi^{2}=3.94, p=0.047\right)$. Almost equal numbers of patients in each group required unscheduled intravenous rehydration during antibiotic treatment.

Of the 246 study patients, 138 had classical $V$ cholerae and 108 had the El tor biotype isolated in their stools. Excretion of $V$ cholerae in the stool was prolonged in both groups of patients receiving doxycycline (table III). Patients treated with doxycycline also had a higher incidence of bacteriological relapse and failure than those treated with tetracycline. The proportion of patients in whom bacteriological relapse and failure occurred was higher in both doxycycline groups compared with the tetracycline group $\left(\chi^{2}=\right.$ $3 \cdot 20, \mathrm{p}=0.07$ with $200 \mathrm{mg}$ doxycycline and $\chi^{2}=7 \cdot 38$, $\mathrm{p}=0.006$ with $300 \mathrm{mg}$ doxycycline). Plasma specific gravity and packed cell volume were similar in the three treatment groups.

\section{Discussion}

The study showed that $300 \mathrm{mg}$ doxycycline is as effective as standard tetracycline treatment in terms of stool output and need for oral rehydration solution. No significant difference in duration of diarrhoea was observed among the groups. Treatment with intravenous fluid had to be restarted in some patients in each group during maintenance with glucose oral rehydration solution, although all had initial intravenous rehydration. This is not unusual for patients with cholera with severe purging. ${ }^{710}$ The duration of excretion of vibrio after doxycycline treatment was longer than that with tetracycline treatment. It is not clear, however, if these patients with prolonged excretion represent an important public health risk to the community.

The primary mode of treatment in acutely de- hydrating cholera remains early rehydration and maintenance with intravenous or oral fluid treatment, or both. A single dose of $300 \mathrm{mg}$ of doxycycline was an acceptable alternative to standard treatment with tetracycline despite a somewhat longer duration of excretion of vibrio. This regimen would help reduce problems of patient compliance and simplify logistics in treating patients with cholera, especially in the community and during epidemics.

In Bangladesh the total cost of a course of tetracycline is 49 cents whereas a single $200 \mathrm{mg}$ dose of doxycycline would cost 12 cents and a $300 \mathrm{mg}$ dose 17 cents. In a busy hospital like this centre, which treats 14148 patients with cholera annually, the cost of antibiotics for these patients could be reduced from $\$ 6862$ to $\$ 2467$ by changing to single dose doxycycline.

The present study was conducted only in adults with proved cholera. Although tetracycline is not recommended for use in children, because of the lifethreatening nature of cholera and the effectiveness of tetracycline and doxycycline further study with single dose doxycycline in children should be considered.

This study was supported by a grant from the World Health Organisation and the International Centre for Diarrhoeal Disease Research, Bangladesh.

We thank Pfizer, Bangladesh, for providing free the medicine and placebo, Dr Maksudar Rahman for statistical advice on sample size and randomisation, and $\mathrm{Dr} D$ Mahalanabis for statistical analyses and preparation of the manuscript. We also thank Mr Meer Md Ramzan Ali for secretarial work.

1 Lindenbaum J, Greenough WB, Islam MR. Antibiotic therapy of cholera Bull WHO 1967;36:871-83.

Wallace CK, Anderson PN, Brown TC, et al. Optimal antibiotic therapy in cholera. Bull WHO 1968;39:239-45.

3 Sack DA, Islam S, Rabbani H, Islam R. Single dose doxycycline for cholera. Antimicrob Agents Chemother 1978;14:462-4.

4 De S, Chaudhuri A, Dutta D, De SP. Doxycycline in the treatment of cholera. Bull WHO 1976;54:177-9.

5 Rahaman MM, Majid MA, Alam AKMJ, Islam MR. Effects of doxycycline in actively purging cholera patients: a double blind trial. Antimicrob Agents Chemor 1976;10:610-2

6 McCormack WM, Choudhury AN, Jahangir NA, Ahmed ABF, Mosley WH Tetracycline prophylaxis in families of cholera patients. Bull WHO 1968;38 787-92.

7 Nalin DR, Cash RA. Oral maintenance therapy for cholera in adults. Lancet 1968;ii:370-3.

8 Sack RB, Cassels J, Mitra R, et al. The use of oral replacement solutions in the treatment of cholera and other severe diarrhoeal disorders. Bull WHO 1970;43:351-60.

9 Palmer DL, Koster FT, Islam AFMR, Rahman ASMM, Sack RB. Comparison of sucrose and glucose in the oral electrolyte therapy of cholera and other severe diarrheas. N Engl f Med 1977;297:1107-9.

10 Patra FC, Sack DA, Islam A, Alam AN, Mazumder RN. Oral rehydration formula containing alanine and glucose for treatment of diarrhoea: formula containing alanine and glucose

(Accepted 17 April 1990 